This item was submitted to Loughborough's Research Repository by the author.

Items in Figshare are protected by copyright, with all rights reserved, unless otherwise indicated.

\title{
Subjective ratings of whole-body vibration for single- and multi-axis motion
}

PLEASE CITE THE PUBLISHED VERSION

http://dx.doi.org/10.1121/1.3654014

\section{PUBLISHER}

(C) Acoustical Society of America

\section{VERSION}

AM (Accepted Manuscript)

\section{LICENCE}

CC BY-NC-ND 4.0

\section{REPOSITORY RECORD}

Mansfield, Neil J., and Setsuo Maeda. 2019. "Subjective Ratings of Whole-body Vibration for Single- and Multi-axis Motion”. figshare. https://hdl.handle.net/2134/11821. 
This item was submitted to Loughborough's Institutional Repository (https://dspace.lboro.ac.uk/) by the author and is made available under the following Creative Commons Licence conditions.

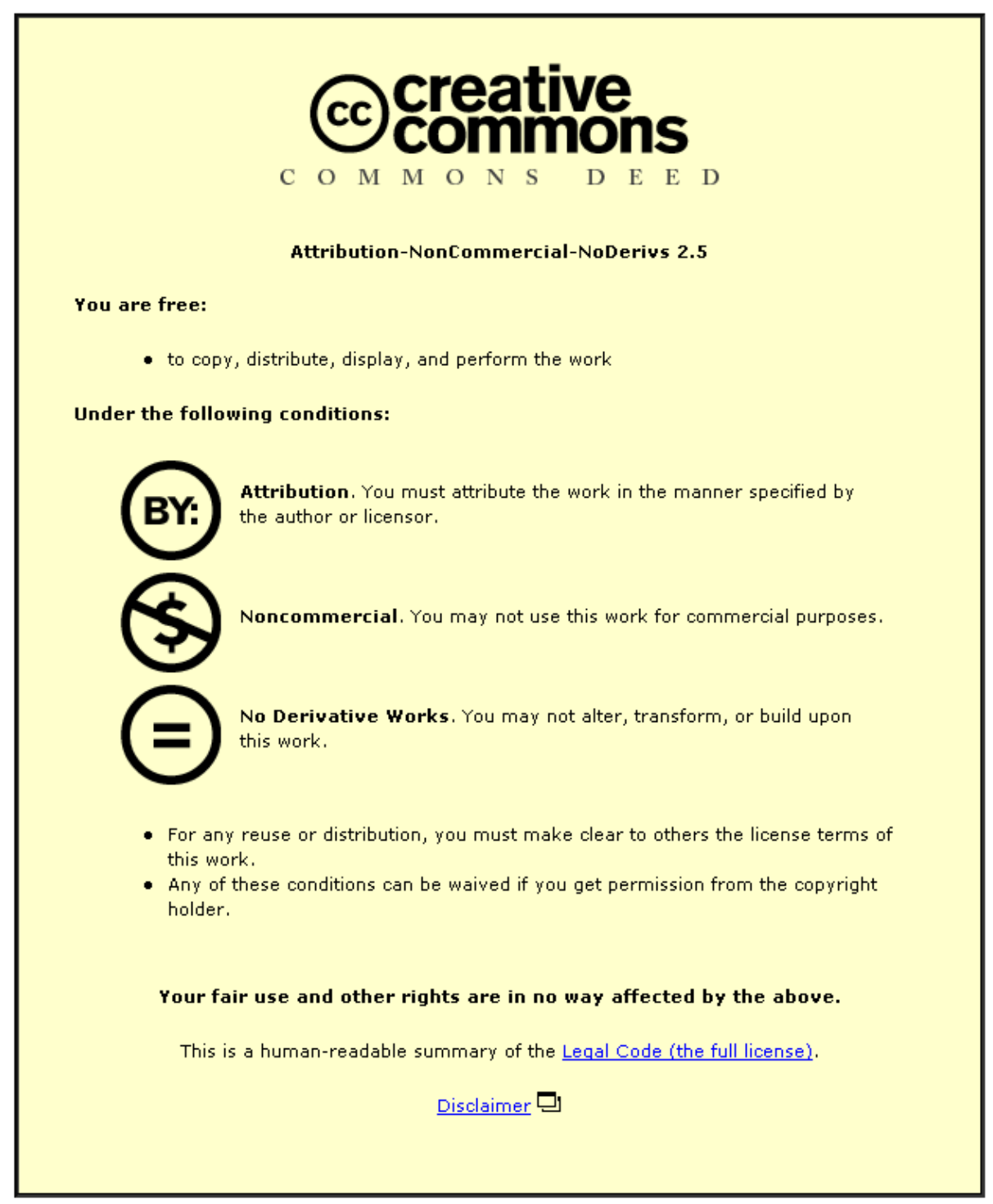

For the full text of this licence, please go to: http://creativecommons.org/licenses/by-nc-nd/2.5/ 
Subjective ratings of whole-body vibration for single- and

\author{
multi-axis motion
}

(Received 21 June 2011; revised 30 September 2011; accepted 30 September 2011)

J. Acoust. Soc. Am. 130 (6), December 2011

Pages: $3723-3728$

DOI: 10.1121/1.3654014 
Subjective ratings of whole-body vibration for single- and multi-axis motion

\author{
Neil J Mansfield \\ Environmental Ergonomics Research Centre \\ Loughborough Design School \\ Loughborough University \\ Loughborough \\ LE11 3TU, UK \\ Setsuo Maeda \\ Faculty of Applied Sociology \\ Kinki University \\ Kowakae 3-4-1, Higashiosaka City \\ 577-8502 Japan
}

Running head: Subjective ratings of multi-axis motion 


\section{ABSTRACT}

Real-world whole-body vibration exposures comprise motion in fore-aft, lateral and vertical directions simultaneously. There can also be components of roll, pitch and yaw. If evaluating vibration with respect to human response, most investigators will use methods defined in ISO 2631-1. This uses frequency weightings that were originally derived from laboratory studies of the subjective responses to vibration in one direction at a time. This paper describes experiments carried out using a 6 degree-of-freedom vibration simulator to validate the applicability of ISO 2631-1 in multi-axis environments. 15 subjects were exposed to 87 stimuli comprising single-axis, dual-axis and tri-axial random vibration, to which they were required to produce subjective ratings. It is shown that in this study the root-sum-of-squares method of summation of subjective ratings in individual axes was an adequate technique for prediction of subjective rating of multiaxis vibration. Better agreement between objective and subjective measures of vibration was obtained for unweighted vibration than for frequency weighted signals. The best agreement for this study was achieved when axis multiplying factors were set at 2.2 and 2.4 for $x$ - and $y$-axis vibration respectively. Different values could be appropriate for other postures, seats, and vibration conditions and should be determined in future studies.

PACS numbers: 43.40.Ng, 43.66.Wv 


\section{INTRODUCTION}

Most whole-body vibration exposures comprise vibration in multiple axes and with complex signals. Methods defined in ISO 2631-1 (1997) provide techniques by which such complex multi-axis stimuli can be condensed into single values and these can be used to provide a qualitative indication of the expected comfort and perception. Multifrequency and multi-directional vibration is considered by the use of frequency weightings and multiplying factors whereby the relative contribution of vibration at different frequencies is modelled dependent on the direction of the vibration (Rimell et

al. 2007). The same frequency-model is used irrespective of vibration magnitude, vibration waveform or application for the assessment (e.g. for prediction of subjective or health effects). Consideration of multi-axis vibration is achieved by either selecting the most severe axis of vibration (for health effects) or summing the vibration in each direction, usually using a root sum-of-squares (r.s.s.) technique.

Almost all previous laboratory work considering the subjective response of the seated human to whole-body vibration has been completed using single-axis vibration generation systems. Whilst such an approach is attractive in terms of cost, simplicity and the ease of carefully controlling the stimuli to which subjects are exposed, it is not representative of environments in which individuals are exposed to vibration. Whilst these studies allowed for understanding of the fundamentals of human response to vibration, validation in multi-axis environments is scarce in the literature. Studies on the subjective response to vibration which have considered multi-axis vibration have usually 
only considered two axes of vibration at any one time, have only considered single frequency vibration (sinusoids), and have generally used the method of adjustment psychophysical method (e.g. Griffin and Whitham, 1977; Fairley and Griffin, 1988; Shoenberger, 1987; Shoenberger 1988; Mistrot et al. 1990; Griefahn and Brode, 1999; Mansfield and Maeda, 2005; Forta et al. 2008). The methods for evaluating the subjective response of the seated person to complex multi-axis stimuli still require validation such that the boundaries of their applicability can be established.

This paper reports an experiment with the aim of providing evidence to validate the methods specified in ISO 2631-1 by using a magnitude estimation protocol for broadband single-axis, dual-axis and tri-axial vibration (e.g. Verillo, et al., 1969, Stevens, 1975).

\section{METHODS}

An experiment was performed in order to investigate the subjective response of subjects to multi-axis vibration. Fifteen subjects participated in the experiment. Subjects were all male and had a mean age of 24.5 years (s.d. 4.0 years), a mean stature of $171 \mathrm{~cm}$ (s.d. $5.8 \mathrm{~cm}$ ) and a mean weight of $64.3 \mathrm{~kg}$ (s.d. $8.9 \mathrm{~kg}$ ). Vibration was generated using a 6 degree-of-freedom multi-axis shaker, driven by seven electrodynamic actuators and measured using a Brüel and Kjaer 4326A triaxial accelerometer amplified using a Nexus charge amplifier. Acceleration signals were acquired to computer at 512 samples per second via anti-aliasing filters set at $170 \mathrm{~Hz}$. 
Cross-talk between measurements of vibration in orthogonal axes consists of the true cross-talk (i.e. unwanted vibration in directions other than that being tested), cross-axis response of the accelerometers, accelerometer misalignment errors, and background noise in the system and was less than 5\% (Figure 1).

Figure 1 about here

Subjects sat on a flat horizontal seat with dimensions of $600 \mathrm{~mm}(w) \times 400 \mathrm{~mm}$ (d) which was $540 \mathrm{~mm}$ above the footrest that moved with the seat. No backrest was used in the experiment and no cushion was present on the seat surface. Subjects sat in a relaxed upright posture with hands lightly resting on the thighs (Figure 2).

Figure 2 about here

Subjects were exposed to 3 repeats of 29 different random vibration stimuli with equal energy at each frequency from 1 to $20 \mathrm{~Hz}$ (a total of 87 exposures). This frequency range was selected to encompass the main body resonances, and the frequency range over which the simulator had its optimal performance. These were made up of singleaxis, dual-axis and tri-axial vibration. Single-axis motion was generated at 0.2, 0.4 and $0.8 \mathrm{~ms}^{-2}$ r.m.s. in each direction (unweighted) with additional stimuli at 1.0 and $1.2 \mathrm{~ms}^{-2}$ r.m.s. in the vertical direction. Dual-axis vibration was generated using $0.4 \mathrm{~ms}^{-2}$ vibration in each pair of orthogonal axes. Tri-axial vibration was generated using 
combinations of $0.2,0.4$ and $0.8 \mathrm{~ms}^{-2}$ r.m.s. in each direction. Each stimulus lasted 10 seconds typical of longer stimuli for whole-body vibration perception studies (Griffin, 1990). Stimuli were separated by a 5 -second pause during which they gave subjective responses. Stimuli are summarised in Table 1 and were presented in a balanced random order to mitigate the effects of fatigue.

Table 1 about here

The dependent variable for the experiment was a subjective rating of vibration magnitude. Subjects were required to perform a magnitude estimation task according to the following instructions based on Stevens (1975):

"You will be presented with a series of vibration stimuli in irregular order. Your task is to tell how intense they seem by assigning numbers to them. Call the first stimulus any number that seems appropriate to you. Then assign successive numbers in such a way that they reflect your subjective impression. There is no limit to the range of numbers that you may use. You may use whole numbers, decimals or fractions. Try to make each number match the intensity of vibration as you perceive it."

Each subject's individual responses were normalised by dividing by the geometric mean of all of their responses to enable comparison between subjects using different ranges of numerical values. The experiment was approved by the Research Ethic Committee of the National Institute of Industrial Health, Kawasaki, Japan. 


\section{RESULTS}

As expected, subjective ratings of vibration intensity generally increased with each increase in vibration magnitude (Figure 3). Similar normalised ratings were obtained for each direction of vibration at $0.2,0.4$, and $0.8 \mathrm{~ms}^{-2}$ r.m.s. $(p=0.85,0.93,0.53$ respectively, Friedman).

Figure 3 about here

For dual-axis vibration subjective ratings of intensity were significantly greater for the $x-z$ vibration (median 1.07) than for the $x-y$ ratings (median $0.91 ; p<0.005$, Wilcoxon) and the $y-z$ ratings (median 0.96; $p<0.05)$ (Figure 4). Differences were not significant between the $x-y$ and $y-z$ ratings $(p=0.096)$. Subjective ratings measured using dualaxis vibration were significantly greater than subjective ratings measured for any component part of the vibration ( $p<0.05$ or $p<0.005$, Wilcoxon): e.g. ratings for dualaxis $0.4 \mathrm{~ms}^{-2} \mathrm{x}-\mathrm{y}$ vibration were greater than single-axis ratings for $0.4 \mathrm{~ms}^{-2}$ in either the $x$ - or y-axis.

Figure 4 about here 
For tri-axial vibration, subjective ratings of vibration intensity increased with vibration magnitude, as would be expected (Figure 5). Subjective ratings of vibration intensity measured using tri-axial vibration were significantly greater than subjective ratings measured for any component part of the vibration ( $<<0.01$, Wilcoxon): e.g. ratings for tri-axial $0.4 \mathrm{~ms}^{-2} \mathrm{xyz}$ vibration were greater than single-axis ratings for $0.4 \mathrm{~ms}^{-2}$ in either the $x-, y$ - or z-axis.

Figure 5 about here

ISO 2631-1 recommends that for a 'comfort' assessment, translational vibration in multiple directions can be combined using the r.s.s. method to provide the point vibration total value. If there is no backrest contact then multiplying factors of 1.0 are used for each direction of translational vibration at the seat; if backrest contact is present, but not measured, the horizontal vibration at the seat is scaled by 1.4. For this study there was no backrest contact; therefore, if ISO 2631-1 r.s.s. summation is correct, individual results from single-axis vibration conditions should be able to predict results from the dual and tri-axial vibration conditions by calculating the r.s.s. of the ratings for each vibration component. Median measured subjective responses for single-axis vibration were used to predict the responses of subjects to multi-axis vibration (Figure 6). The r.m.s. percentage difference between the measured and predicted responses was $5.8 \%$ 
Figure 6 about here.

If subjective data from dual-axis motion is combined with the data from the third axis, additional predictions for tri-axial vibration can be tested, by carrying out an r.s.s. summation and comparing with the equivalent tri-axial measurement. xy-dual / z-single, $x z$-dual / $y$-single, and yz-dual / $x$-single combinations generate predictions that have errors of $5.1,5.5$ and $5.2 \%$ respectively.

\section{DISCUSSION}

The responses reported here were based on the mean of three repeats. The mean coefficient of variation for the 27 conditions over all subjects was $26 \%$, demonstrating subject reliability. Any underlying fatigue effects were minimised through the balanced randomised order of presentation of stimuli.

ISO 2631-1 provides guidance on the method of assessing vibration occurring simultaneously in more than on axis. It states that vibration magnitudes in each component axis should be combined using the method of r.s.s. summation. This study has validated that general approach, showing r.s.s. summation of responses to singleaxis vibration predict the response to the equivalent multi-axis stimulus (Figure 6). 
However, these data do not support the use of frequency weightings and multiplying factors as suggested in ISO 2631-1. If the standard frequency weightings were appropriate then subjective ratings for the $x$ - and $y$ - single-axis stimuli should have been rated as less intense than the $z$ - single-axis stimuli and the dual-axis $x-y$ stimuli should have been rated as less intense than the dual-axis stimuli containing vertical motion. In this experiment, frequency weighting the data caused a divergence in the results (Figure 7). These results should be interpreted with caution, as the frequency content of the vibration stimuli were band-limited random and other stimuli with different frequency content could produce different sensations of discomfort. In order to compensate for the differences in the subjective ratings in comparison to the weighted values, multiplying factors could be applied to increase the weighting for $\mathrm{x}$ - and $\mathrm{y}$-axis vibration.

Figure 7 about here

Using random vibration stimuli with similar spectra to those used here, but using a category rating scale method, Maeda and Mansfield (2005) showed nominally identical relative ratings of vibration magnitude for vibration in single-axes but occurring in different directions. It was demonstrated that the ISO 2631-1 frequency weighting filters caused a divergence of predicted and measured subjective ratings compared to 
using unweighted vibration, rather than convergence as would be expected. Despite using different methods, the results parallel those reported here. Using sinusoidal vibration and an intensity matching method, Griefahn and Bröde (1999) also concluded that ISO 2631-1 relatively underestimates the discomfort caused by horizontal vibration. Marjanen et al. (2010) used a cross-modal matching method to determine the relative contribution of translational and rotational vibration to discomfort for subjects sitting in a vehicle seat and showed that the best agreement between subjective responses and vibration magnitudes occurred with multiplying factors of $2.7(x)$ and $1.8(y)$.

The best combination of multiplying factors for frequency-weighted $x$ - and $y$-axis vibration was determined by fixing the vertical factor to 1.0 and calculating correlation coefficients for all combinations of multiplying factors for $x$ - and $y$-vibration. These data showed that the best agreement occurred for an x-factor of 2.2 and $y$-factor of 2.4 (Figure 8). Correlation was better for multiplying factors suggested by Marjanen than for the ISO 2631-1 factors of $1.4(x, y)$ and $1.0(z)$.

Figure 8 about here.

It is recommended that further work is completed in order to provide additional evidence of multiplying factors that should be used to determine subjective responses to multiaxis vibration. 


\section{CONCLUSIONS}

An experiment has been conducted with the aim of validating the methods for assessing the subjective effects of multi-axis vibration as defined in ISO 2631-1. Similar results were obtained for subjective ratings of random vibration band limited at 1 and $20 \mathrm{~Hz}$ in the $x-, y-$, and $z$-axes at each of three magnitudes of vibration. An r.s.s. model was able to predict the subjective rating of multi-axis vibration from individual measurements of vibration in each component axis. Frequency weighting the vibration stimuli used in this experiment caused a divergence between the measured vibration magnitudes and subjective ratings. The sensitivity of the subjects to horizontal vibration was under estimated in ISO 2631-1. Further research is required to confirm the findings reported here and to develop an improved method of predicting subjective responses to multi-axis whole-body vibration.

\section{ACKNOWLEDGEMENT}

This research was supported by the Japan Ministry of Health, Labour and Welfare. 


\section{REFERENCES}

Fairley, T.E. and Griffin, M.J. (1988). Predicting the discomfort caused by simultaneous vertical and fore-and-aft whole-body vibration. Journal of Sound and Vibration 124(1), 141-156.

Forta N.G., Morioka M. and Griffin M.J. (2009) Difference thresholds for the perception of whole-body vertical vibration: dependence on the frequency and magnitude of vibration. Ergonomics, 52(10), $1305-1310$.

Griefahn, B. and Brode, P. (1999) The significance of lateral whole-body vibrations related to separately and simultaneously applied vertical motions. A validation study of ISO 2631. Applied Ergonomics 30, 505-513.

Griffin, M.J. (1990). Handbook of human vibration. Academic Press, London. 988p.

Griffin, M.J. and Whitham, E.M. (1977). Assessing the discomfort of dual-axis wholebody vibration. Journal of Sound and Vibration 54(1), 107-116.

International Organization for Standardization (1997). Mechanical vibration and shock evaluation of human exposure to whole-body vibration: ISO2631-1.

Maeda, S. and Mansfield, N.J. (2005). Effect of direction on subjective evaluation of whole-body vibration. 13th Japan Group Meeting on Human Response to Vibration, Osaka, Japan, 3-5 August 2005, 1-11. 
Mansfield N.J. and Maeda S. (2005) Equal sensation curves for whole-body vibration expressed as a function of driving force. Journal of the Acoustical Society of America 117(6) 3853-3859.

Marjanen Y. and Mansfield N.J. (2010) Relative contribution of translational and rotational motion to discomfort. Industrial Health 48, 519-529.

Mistrot, P., Donati, P., Galmiche, J.P. and Florentin, D. (1990) Assessing the discomfort of the whole-body multi-axis vibration: laboratory and field experiments. Ergonomics 33(12) 1523-1536.

Rimell A.N. and Mansfield N.J. (2007) Design of digital filters for frequency weightings required for risk assessments of workers exposed to vibration. Industrial Health 45(4), $512-9$.

Shoenberger, R.W. (1987) Intensity judgments of vibrations in the $Y$ axis, $Z$ axis, and $Y$ plus-Z axes. Aviat Space Environ Med 58(8):783-7.

Shoenberger, R.W. (1988) Intensity judgments of vibrations in the X axis, Z axis, and Xplus-Z axes. Aviat Space Environ Med 59(8):749-53.

Stevens, S.S. (1975). Psychophysics: introduction to its perceptual, neural, and social prospects. Wiley-Interscience. 336p.

Verillo, R.T., Fraioli, A.J. and Smith, R.L. (1969). Sensation magnitude of vlbrotactile stimuli. Perception \& Psychophysics 6(6A): 366-72. 
Table 1. Summary of stimuli used in the experiment

\begin{tabular}{|c|c|c|c|c|c|c|}
\hline & \multirow[b]{2}{*}{ Stimulus } & \multicolumn{5}{|c|}{ Vibration magnitude ( $\mathrm{ms}^{-2}$ r.m.s.) } \\
\hline & & $\mathrm{x}$-axis & $y$-axis & z-axis & $\begin{array}{l}\text { r.s.s. } \\
\sum \text { axes }\end{array}$ & $\begin{array}{l}\text { r.s.s. weighted } \\
\Sigma \text { axes }\end{array}$ \\
\hline \multirow{11}{*}{$\begin{array}{l}\text { Single-axis } \\
\text { stimuli }\end{array}$} & 1 & 0.20 & - & - & 0.20 & 0.08 \\
\hline & 2 & - & 0.20 & - & 0.20 & 0.08 \\
\hline & 3 & - & - & 0.20 & 0.20 & 0.17 \\
\hline & 4 & 0.40 & - & - & 0.40 & 0.16 \\
\hline & 5 & - & 0.40 & - & 0.40 & 0.16 \\
\hline & 6 & - & - & 0.40 & 0.40 & 0.34 \\
\hline & 7 & 0.80 & - & - & 0.80 & 0.31 \\
\hline & 8 & - & 0.80 & - & 0.80 & 0.31 \\
\hline & 9 & - & - & 0.80 & 0.80 & 0.69 \\
\hline & 10 & - & - & 1.00 & 1.00 & 0.86 \\
\hline & 11 & - & - & 1.20 & 1.20 & 1.03 \\
\hline \multirow[t]{3}{*}{ Dual-axis stimuli } & 12 & 0.40 & 0.40 & - & 0.57 & 0.22 \\
\hline & 13 & 0.40 & - & 0.40 & 0.57 & 0.38 \\
\hline & 14 & - & 0.40 & 0.40 & 0.57 & 0.38 \\
\hline \multirow{15}{*}{ Tri-axial stimuli } & 15 & 0.20 & 0.20 & 0.20 & 0.35 & 0.20 \\
\hline & 16 & 0.20 & 0.20 & 0.40 & 0.49 & 0.36 \\
\hline & 17 & 0.20 & 0.40 & 0.20 & 0.49 & 0.24 \\
\hline & 18 & 0.40 & 0.20 & 0.20 & 0.49 & 0.24 \\
\hline & 19 & 0.40 & 0.40 & 0.20 & 0.60 & 0.28 \\
\hline & 20 & 0.40 & 0.20 & 0.40 & 0.60 & 0.39 \\
\hline & 21 & 0.20 & 0.40 & 0.40 & 0.60 & 0.39 \\
\hline & 22 & 0.40 & 0.40 & 0.40 & 0.69 & 0.41 \\
\hline & 23 & 0.40 & 0.40 & 0.80 & 0.98 & 0.72 \\
\hline & 24 & 0.40 & 0.80 & 0.40 & 0.98 & 0.49 \\
\hline & 25 & 0.80 & 0.40 & 0.40 & 0.98 & 0.49 \\
\hline & 26 & 0.80 & 0.80 & 0.40 & 1.20 & 0.56 \\
\hline & 27 & 0.80 & 0.40 & 0.80 & 1.20 & 0.77 \\
\hline & 28 & 0.40 & 0.80 & 0.80 & 1.20 & 0.77 \\
\hline & 29 & 0.80 & 0.80 & 0.80 & 1.39 & 0.82 \\
\hline
\end{tabular}


Figure captions

Figure 1. Example power spectral density (PSD) for single axis z-direction vibration. The figure also shows PSDs measured simultaneously in orthogonal directions.

Figure 2. Laboratory set-up showing seating posture.

Figure 3. Normalised subjective ratings of vibration intensity for 15 subjects exposed to single-axis vibration in the $x-, y$ - and $z$-axes. Each data point represents the mean of three repeats. Lines connect data points for each subject.

Figure 4. Normalised subjective ratings of vibration intensity for 15 subjects exposed to dual-axis vibration at $0.4 \mathrm{~ms}^{-2}$ r.m.s. in the $x-y, x-z$ and $y-z$ axes. Each data point represents the mean of three repeats.

Figure 5. Normalised subjective ratings of vibration intensity for 15 subjects exposed to 15 tri-axial vibration stimuli. Each data point represents the mean of three repeats. Regression lines are shown for each subject. 
Figure 6. Comparison of median measured normalised responses for subjects exposed to dual-axis and tri-axial vibration, and predicted normalised responses based on results from single-axis vibration components.

Figure 7. Median normalised ratings of vibration intensity for single-axis, dual-axis and tri-axial r.s.s. vibration for weighted and unweighted data.

Figure 8. Contour map showing correlation coefficients for subjective response compared to vibration magnitude scaled with a range of values of $x$-axis and $y$-axis multiplier. The factors in ISO $2631-1(1.0,1.0$ and $1.4,1.4)$ and those suggested in Marjanen $(2.7,1.8)$ are highlighted. 


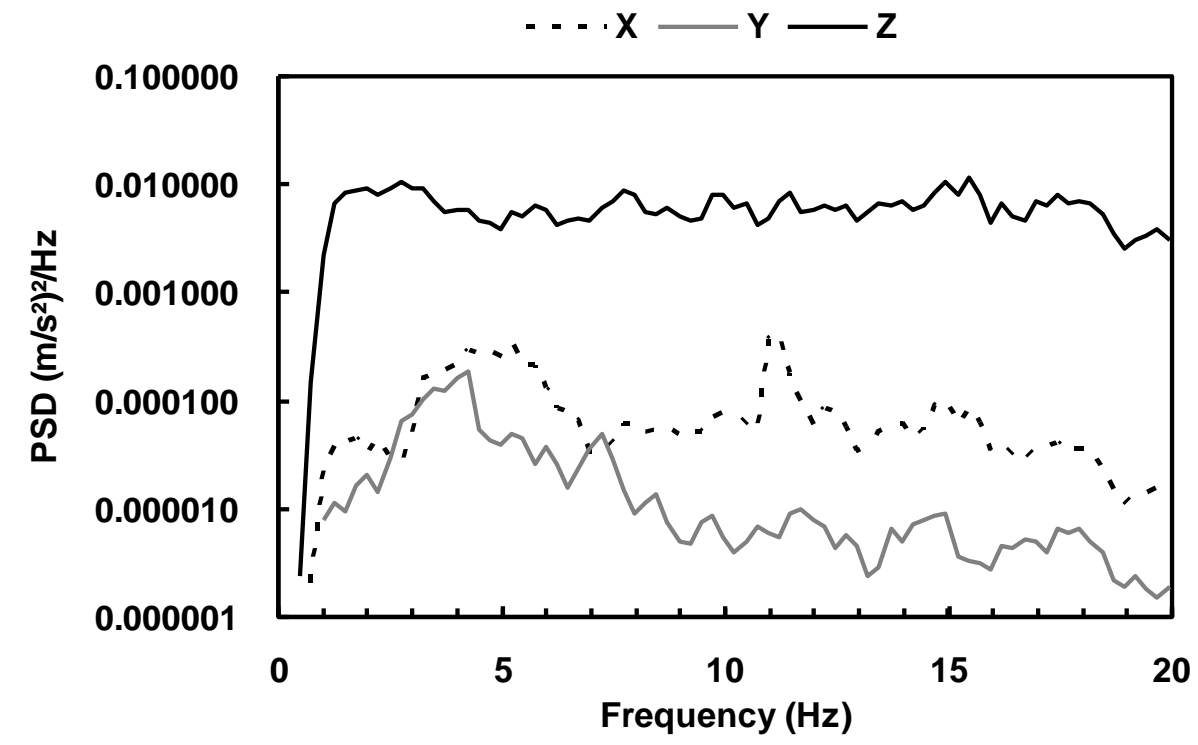

Figure 1 


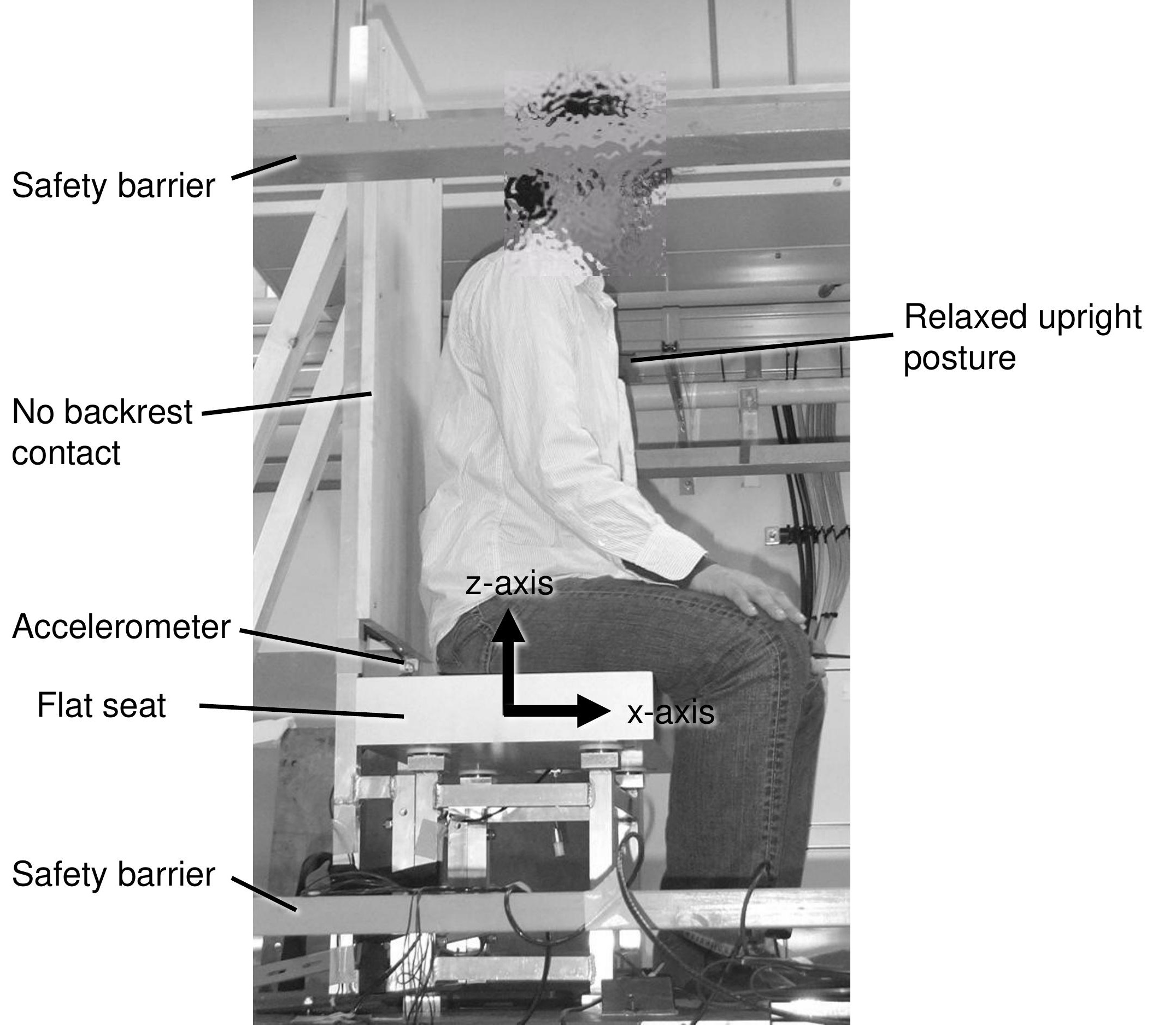




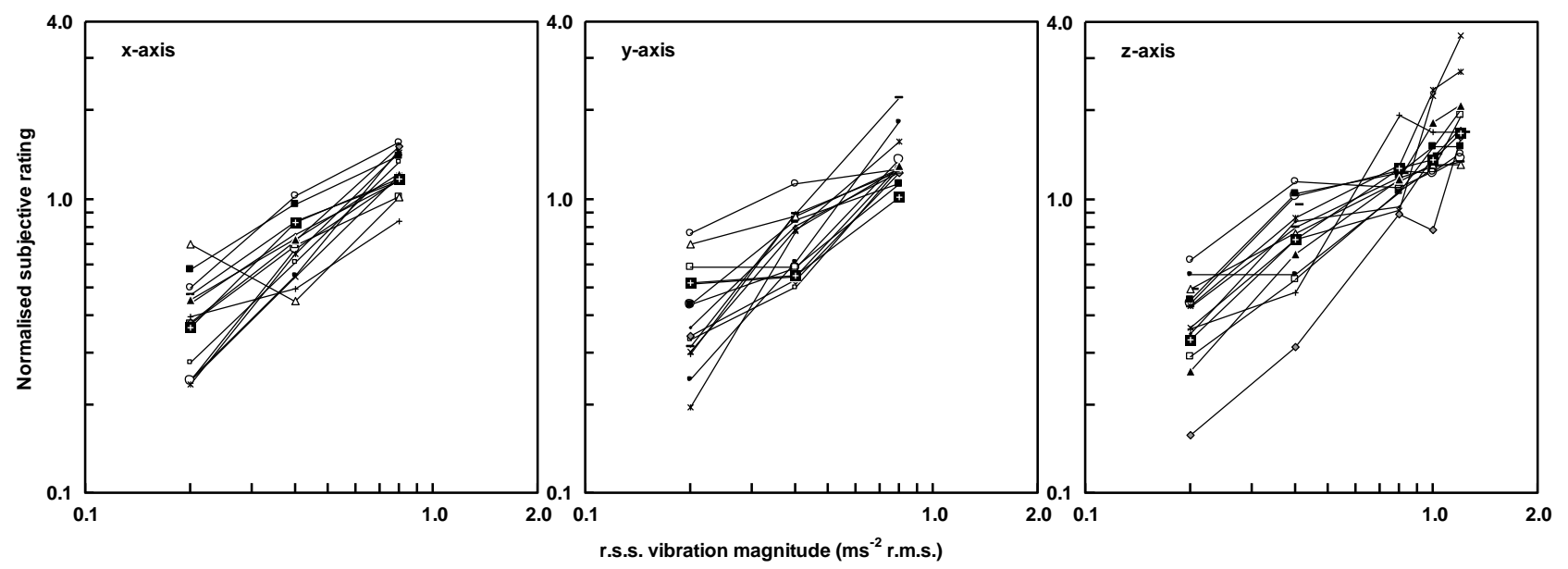

Figure 3. 


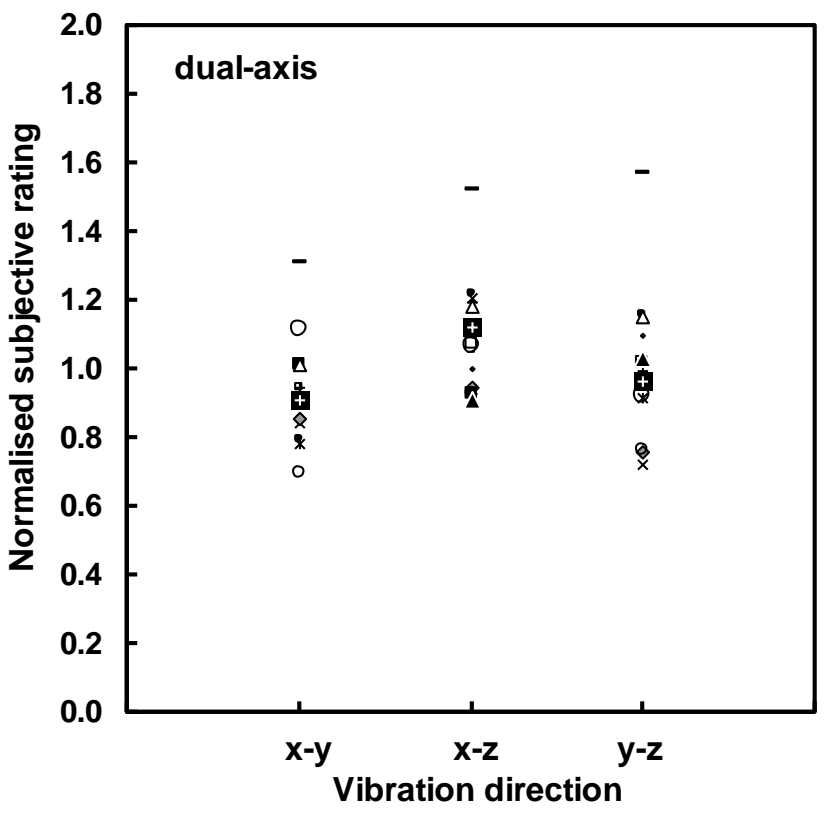

Figure 4. 


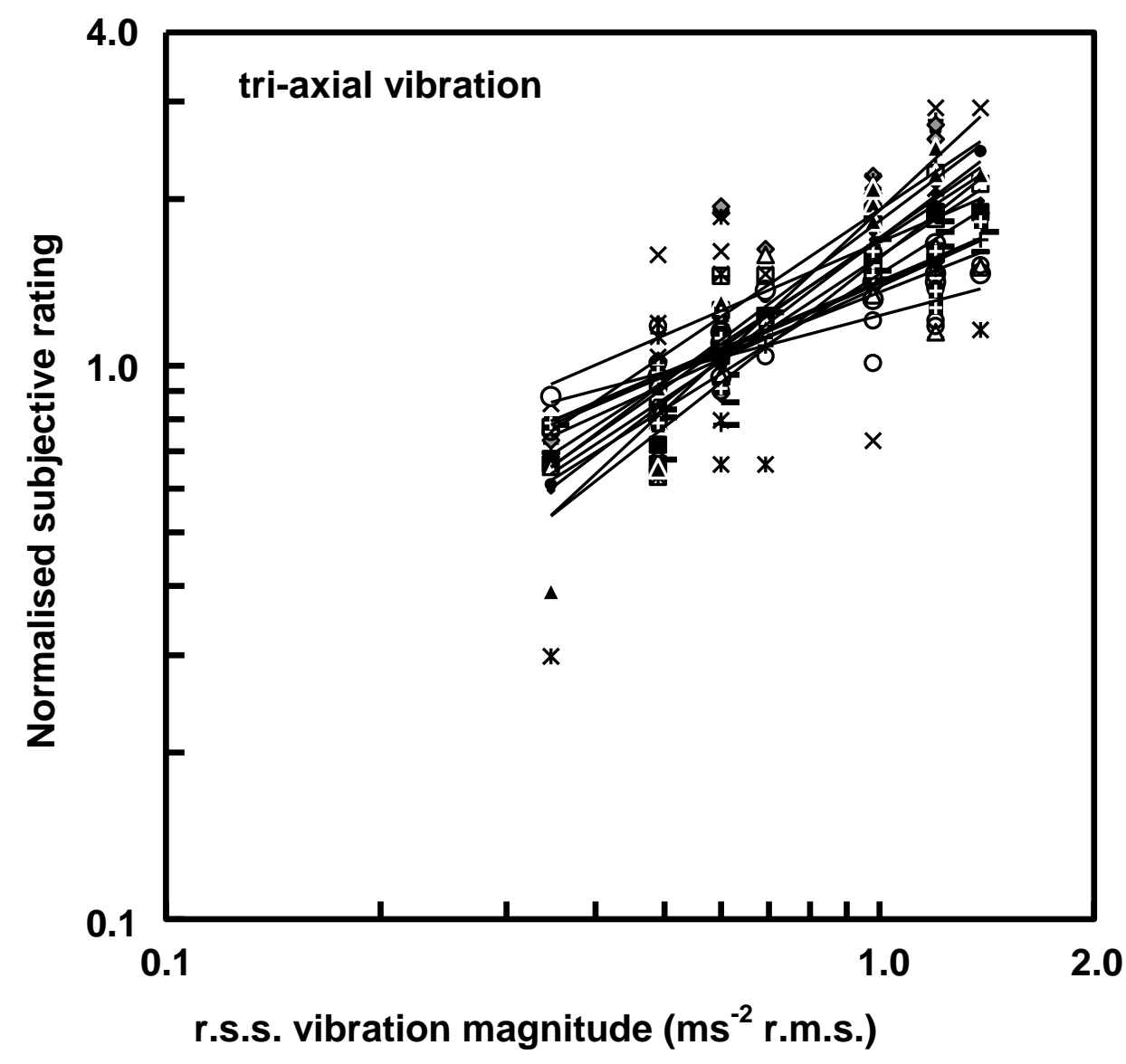

Figure 5. 


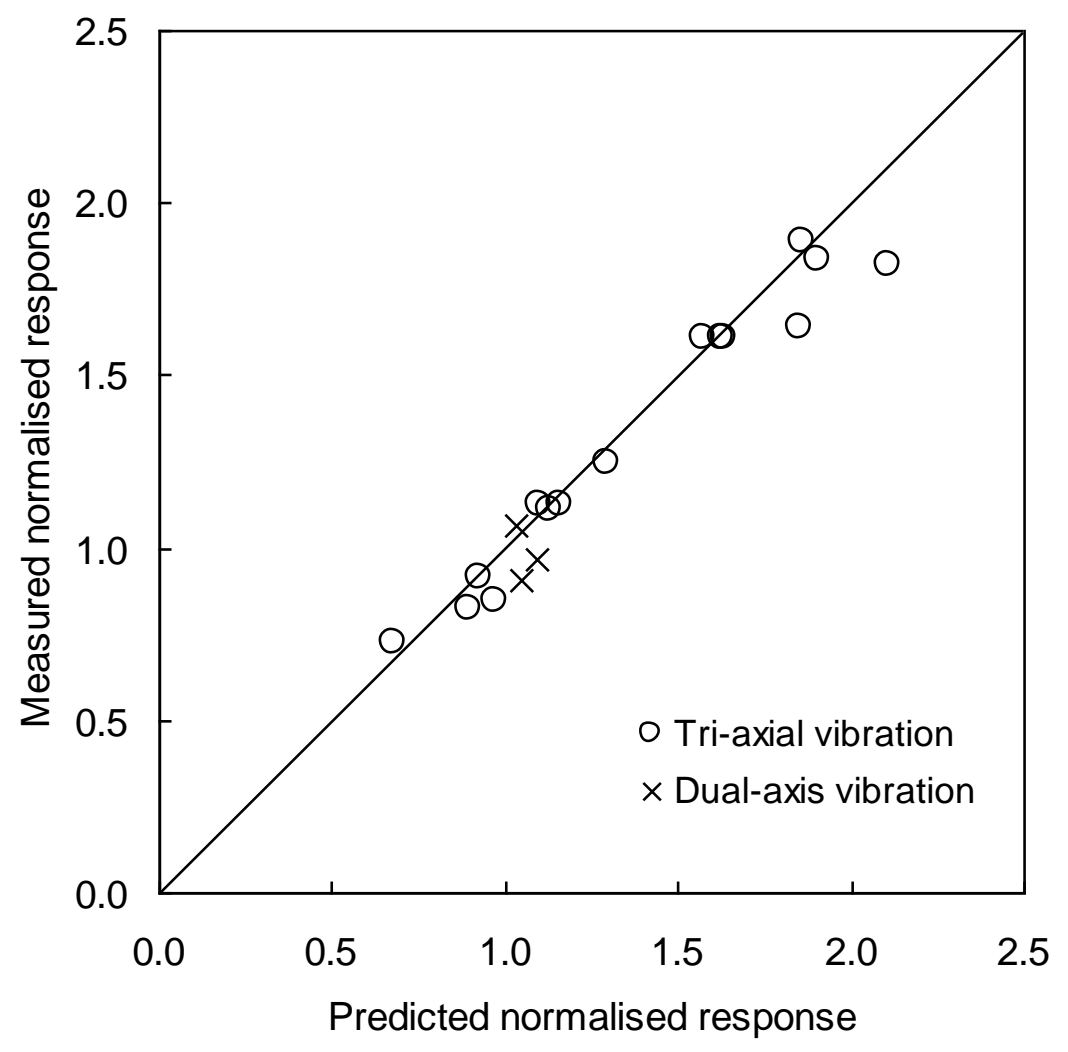

Figure 6. 
Figure 7
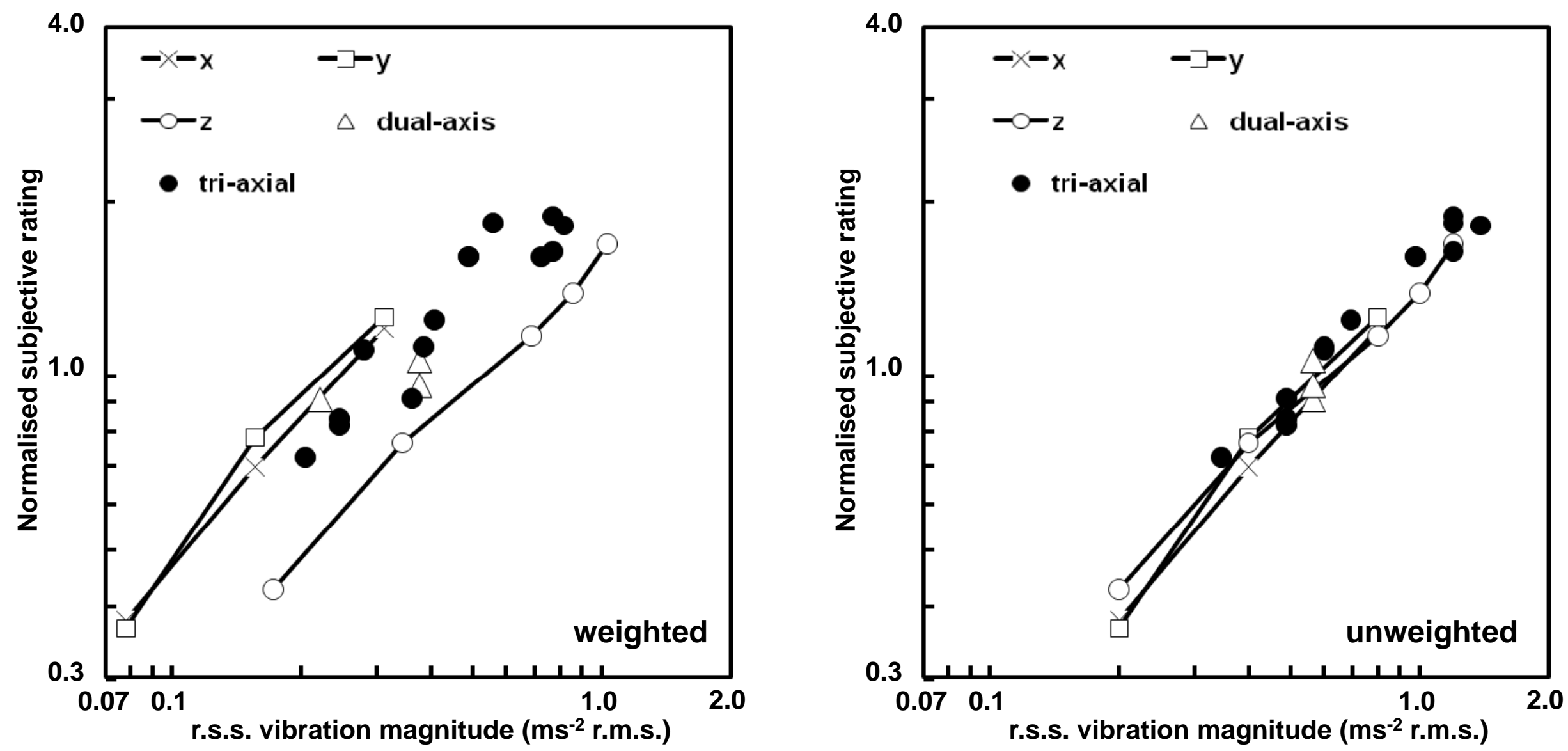
Figure 8

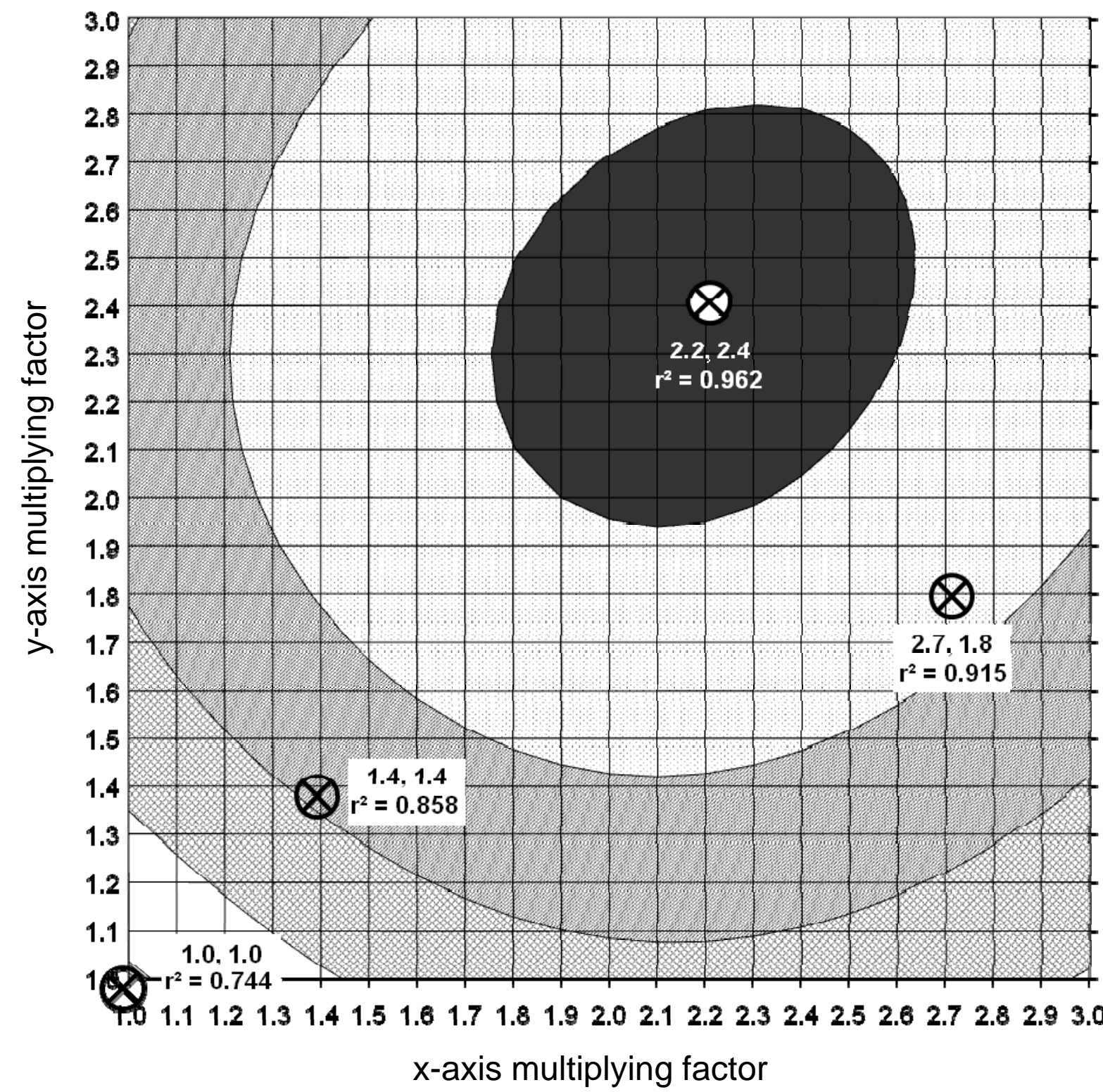

ㅁ.95-1 ه0.9-0.95 च 0.85-0.9 ه0.8-0.85 口0.75-0.8 $\$ 0.7-0.75$ 